Article

\title{
Classification of Rainfall Warnings Based on the TOPSIS Method
}

\author{
Sadegh Zeyaeyan ${ }^{1, *}$, Ebrahim Fattahi ${ }^{1}$, Abbas Ranjbar ${ }^{1}$ and Majid Vazifedoust ${ }^{2}$ \\ 1 Atmospheric Science \& Meteorological Research Center, Tehran P.O.Box 14977-16385, Iran; \\ ebfat2002@yahoo.com (E.F.); aranjbar@gmail.com (A.R.) \\ 2 Water Engineering Department, Guilan University, Rasht P.O.Box 41889-58643, Iran; \\ majid.vazifedousd@yahoo.com \\ * Correspondence: s.ziayan@yahoo.com; Tel.: +98-912-241-9907
}

Academic Editor: Christina Anagnostopoulou

Received: 10 February 2017; Accepted: 7 April 2017; Published: 17 April 2017

\begin{abstract}
Extreme weather, by definition, is any unexpected, unusual, unpredictable, severe or unseasonal weather condition. A rainfall event that is considered normal in one region may be considered a torrent in a dry region and may cause flash flooding. Therefore, appropriate weather warnings need to be issued with respect to areas with different climates. Additionally, these alerts should be easy to understand - by clear classification-in order to apply reinforcements. Early warning levels not only depend on the intensity and duration of rainfall events, but also on the initial water stress conditions, land cover situations and degree of urbanization. This research has focused on defining different warning levels in northwest Iran using long-term precipitation data from 87 weather stations well distributed across the study area. Here, in order to determine alert levels, TOPSIS (The Order of Preference by Similarity to Ideal Solution), as one of the most common methods in multi-criteria decision making, has been used. Results show that five main levels of alerts can be derived, leading to the provision of spatial maps. Further, it can be deduced that these levels are highly associated to the location of a region at different times: months/seasons. It has been observed that the issuance of a warning for precipitation should correspond with the location and time. At one location during different seasons, different alert levels would be raised corresponding to the rainfall. It was also concluded that using of fixed alert levels and extending them to larger areas without considering the seasons could be grossly misleading.
\end{abstract}

Keywords: extreme events; TOPSIS; warning; weather; precipitation

\section{Introduction}

Extreme weather events affect many human activities such as the agriculture and horticulture industries, tourism and transportation. From a climate point of view, some events are unexpected and incompatible with the climate conditions of the region; these are considered extreme events. Although extreme events occur rarely, they directly impact on people and vulnerable regions [1]. Extreme temperature and precipitation conditions are the major factors of weather events. Therefore, investigation of extreme climate events is necessary [2]. Numerous extreme weather events such as drought, typhoon and flood have occurred throughout the world and the frequency of events is still rising [3]. From a statistical point of view, quantity of these events placed in the upper and lower of statistical distribution [4]. The occurrence of extreme weather and climate is closely monitored because of the destruction it has caused in the past few years: the loss of human life and the associated cost impact [5]. Such events affect society, the economy and the environment [6]. Besides, social and environmental impacts of extreme events are high on a local scale and can have a significant effect on specific sectors and regions. The trend of extreme climate indexes based on daily time series of 
temperature and precipitation according to observations of more than 100 weather stations in Europe shows that although the average extreme wet index increased between the years 1946 to 1999, this trend has not been significant [7]. Data from the stations in the northwest region of Iran in the period of 2011-2040 were compared with the period of 1961-1990. This comparison shows that increases in temperature and rainfall fluctuations have increased. The extreme precipitation index in most stations has indicated an increase in the number of heavy rainfall days. It confirms increased rainfall fluctuations and extreme events. Some scientists have related extreme events to global warming caused by recent human interference [8]. It is predicted that the risks will increase in the future [9].

Alerts and warnings of heavy rain must be classified because operation forces and people need to know how to react to each condition and respond appropriately. Prediction of rainfall impacts is very necessary for crisis management. There are several methods to determine the alert levels such as fixed amount, top ten percent of data and other statistical methods. Determining the alert levels and their colors is common practice but the methods used to calculate alert level are different. Each method has its advantages and disadvantages. In this paper, the TOPSIS method was suggested to calculate the alert levels.

There are several methods to predict rainfall-runoff. Groundwater level fluctuations are simulated using dendrochronology (tree-rings) and artificial neural network (ANN) to predict drought [10]. Rainfall-runoff modeling was improved in many researches [11-15]. In this study, alert levels for rainfall are calculated without involving any complex aspects.

The fixed extreme precipitation indexes are defined by the working group ETCCDI (the Expert Team on Climate Change Detection Indices). Heavy precipitation is classified equally or more than $10 \mathrm{~mm}$; overly heavy precipitation as equal or more than $20 \mathrm{~mm}$; and very intense precipitation as equal or more than $25 \mathrm{~mm}$, according to this classification [7]. Four alert levels (green, yellow, orange and red) have been classified in the UK Meteorological Office [16]. Three alert levels (yellow, orange and red) have been used in the meteorology of Ireland [17]. Both countries have classifications based on fixed thresholds. However, these criteria cannot be applied in all areas. These classifications have not considered the climate conditions of the study region. For example, $20 \mathrm{~mm}$ of precipitation which is considered very heavy precipitation in the fixed classification, is a normal level of rainfall in high humidity climates. It is therefore important to utilize various methods to determine the alert levels in a given area.

Another definition of extreme events is unusual and severe events that do not match with seasonal events. Extreme events are extracted from historical data distribution [18] and are determined from weather data in each area. By definition, the top ten percent of statistical data are the threshold for issuing the warning [19]. Often, the top ten percent of the defined values are unusual [20]. Different colors are introduced and used for each event type in National Oceanic and Atmospheric Administration (NOAA) [21]. For example, six colors are used for convective phenomena such as tornadoes; nine colors for hydrological phenomena such as flood; and fifteen colors for non-convective phenomena such as strong winds, dust and ice.

This paper aims to determine alert levels based on long-term precipitation amount and its frequency in a region. The TOPSIS method has been used to calculate and determine alert levels. It seems better than the top ten percent of data. Because TOPSIS is a multi-criteria decision analysis method, we can use many parameters to reach a decision. In this paper, precipitation amount and frequency are used as TOPSIS parameters. Heavy rainfall events usually cause flooding and many parameters are involved in the identification of a flood such as land cover, topography, soil penetration and so on. Although the classification of heavy rainfall events without considering flooding is the aim of this study, the TOPSIS method allows other parameters to be added in addition to the rainfall amount and frequency; this capability can be used in future researches. The TOPSIS method presents results by using positive and negative values. It also presents several variables that make the decision-making process easier and faster than other methods, such as AHP (Analytic Hierarchy Process) [22], FDAHP (fuzzy Delphi analytic hierarchy process) and SAW (Simple Additive Weighting method) [23]. 
Weather alerts and warnings should be easy to understand for the general public and appropriate for the climate conditions of the region. Clear and definitive alert levels that are intuitive for the decision makers as well as the general public can significantly reduce the damage caused by extreme events by providing vital information that allows for appropriate preparation.

Finally, different alert levels are suggested in the region of study based on the months and seasons. Warning levels and corresponding colors have been calculated in five different levels for northwest Iran by the TOPSIS statistical method. It was carried out for 87 meteorological stations in all the months and seasons. Alert maps were generated using the kriging interpolation method for five alert levels in northwest Iran for all months and seasons. These maps help crisis management to make best decision. According to the results of this research, in a specific area, warning issuance depends on the amount of precipitation and the season. The TOPSIS method is suggested because it can be improved by adding more parameters that have an effect on floods. The alert levels correspond with floods.

\section{Materials and Methods}

Northwest Iran includes East Azarbayjan, West Azarbayjan, Ardebil and Zanjan provinces. This area is $127,394 \mathrm{~km}^{2}$ and covers approximately 7.7 percent of the country. The study area is located between latitudes $35^{\circ} 32^{\prime} 54^{\prime \prime} \mathrm{N}$ to $39^{\circ} 46^{\prime} 36^{\prime \prime} \mathrm{N}$ and longitudes $44^{\circ} 2^{\prime} 5^{\prime \prime} \mathrm{E}$ to $49^{\circ} 26^{\prime} 27^{\prime \prime} \mathrm{E}$. In total, there were 87 stations which measured rainfall, including rain gauges, climatology and synoptic stations. On average, the stations are located at about $1830 \mathrm{~m}$ above sea level. The highest altitude is $4500 \mathrm{~m}$ above sea level. The altitude of $4.32 \%$ of the area is between 1600 to $2000 \mathrm{~m}$. The daily rainfall data from 87 meteorological stations have been used to classify the alert levels during the statistical period of 1986-2015. Weather stations location, provinces and annual precipitation are shown in Figure 1. Annual precipitation increases from northeast to southeast in this area. In spite of what was expected, maximum rainfall does not occur at the highest locations of this area. In addition, spatial variations of precipitation are too great. Southwest parts receive the maximum precipitation. Maximum precipitation occurs in early December but it occurs in late December and early January in the Southern half is [24]. Statistical characteristics of the precipitation variables of the stations are shown in Table 1.

Table 1. Statistical characteristics of the precipitation variables in northwest Iran (87 stations).

\begin{tabular}{ccccc}
\hline Variables & Mean & Standard Deviation & Maximum & Minimum \\
\hline Annual precipitation $(\mathrm{mm})$ & 327.86 & 81.25 & 727.41 & 212.07 \\
Winter precipitation $(\mathrm{mm})$ & 92.56 & 42.74 & 313.20 & 40.86 \\
Spring precipitation $(\mathrm{mm})$ & 125.62 & 18.13 & 198.21 & 94.79 \\
Summer precipitation $(\mathrm{mm})$ & 20.95 & 16.03 & 109.40 & 3.90 \\
Autumn precipitation $(\mathrm{mm})$ & 88.73 & 28.14 & 211.48 & 49.31 \\
\hline
\end{tabular}

Several statistical tests have been developed that allow the detection of inhomogeneity. Some depend on the metadata $[25,26]$ and the others use these data as additional information when the station history is poorly documented or missing [27,28]. The Kolmogorov-Smirnov test [29] is used to decide whether a sample comes from a population with a specific distribution. There were only small differences between the various test-statistics [27]. Kolmogorov-Smirnov and Run tests have been recommended to evaluate rainfall quality and homogeneity [30-32]. Therefore, the quality and homogeneity of daily data were controlled by the Run test and Kolmogorov-Smirnov test. 


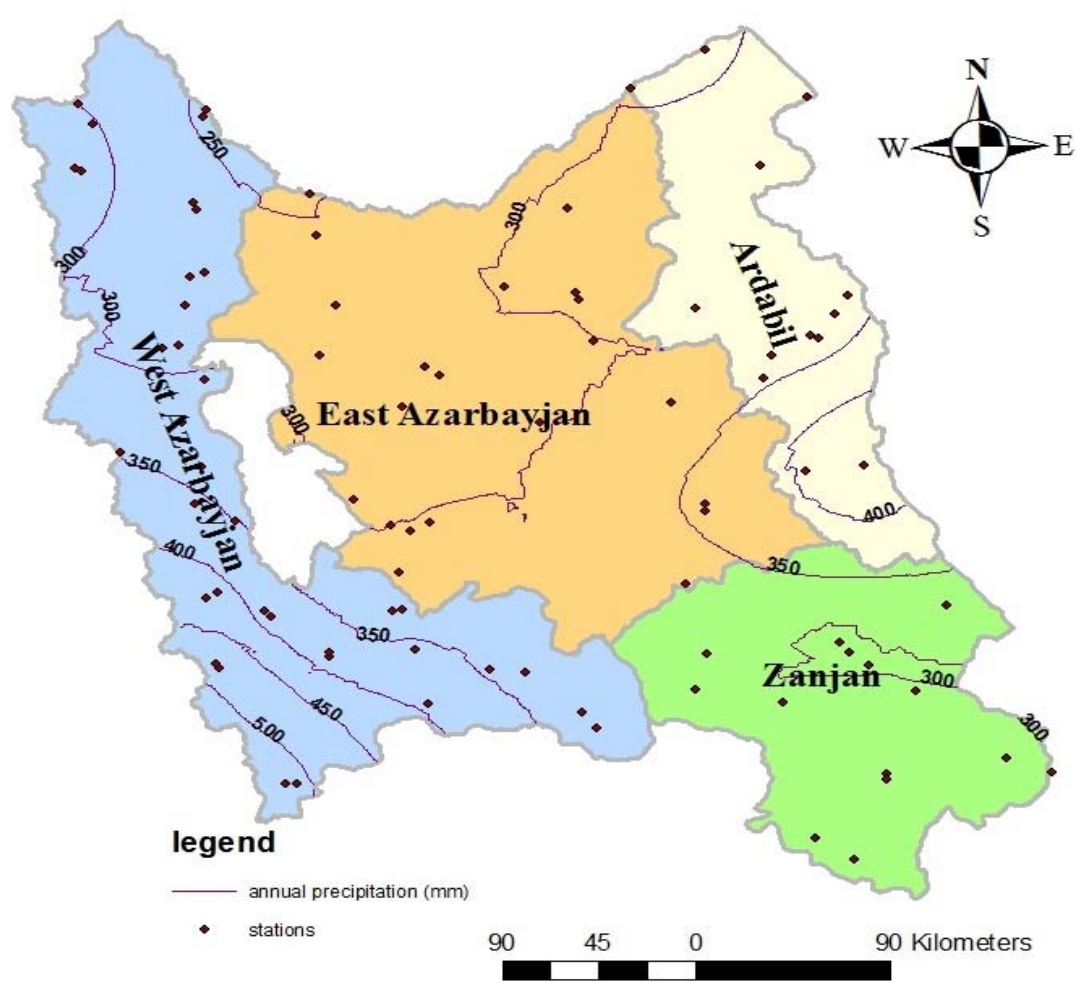

Figure 1. Network stations in northwest Iran and provinces.

TOPSIS is a multi-criteria decision analysis method, which was originally developed by Hwang and Yoon in 1981 [33] with further developments by Yoon in 1987 [34] and Hwang, Lai and Liu in 1993 [35]. This method is recommended by researchers and users in different scientific fields [36,37].

This statistical method is based on the concept that the chosen alternative should have the shortest geometric distance from the positive ideal solution (PIS) and the longest geometric distance from the negative ideal solution (NIS) [38]. Options are ranked based on similarity to an ideal solution, therefore the option that is closer to an ideal solution gets the higher rank. This method of decision analysis has a strong mathematical background. Thus, understanding and compliance of assumptions are very important [39]. Conditions, rules validity and formula [40] will determine the accuracy of the results [41]. It is suggested to use this method only when there is an adequate number of criteria to make a decision on a subject [42]. Data are independent and their increase or decrease is uniform due to the TOPSIS hypothesis [43].

The infrastructure, economy and livelihood of the people of any given region, including road and bridge construction, industry, and agriculture are formed in accordance with the climate of that region. The details of street channels, roofs of buildings, and type of cultivation are related to climate data. The event frequency is assumed to be a parameter that influences the shape and type of infrastructures and human activities. It means that normal climate in an area is defined as the events that happen most frequently and are repeated frequently over a long period of time. Therefore, the amount of rainfall and frequency were selected as criteria for TOPSIS in this study. TOPSIS is deployed in seven steps as described below:

Step One: An evaluation matrix is created. It consists of $m$ alternatives and $n$ criteria. Therefore, we have a $\left(x_{i j}\right)_{m \times n}$ matrix. Amount of precipitation and frequency over 24 hours are known criteria $(n)$, and non-repeating precipitation data at $1 \mathrm{~mm}$ intervals at every station are alternatives $(m)$. 
Step Two: The matrix $\left(x_{i j}\right)_{m \times n}$ is then normalized to form the matrix $\left(r_{i j}\right)_{m \times n^{\prime}}$ using the normalization method in Equation (1). [44]

$$
r_{i j}=\frac{x_{i j}}{\sqrt{\sum_{i=1}^{m} x_{i j}^{2}}}, i=1,2, \ldots, m, j=1,2, \ldots, n
$$

Step Three: Weighting coefficients are calculated. The weighting matrix of the decision is calculated by Equation (2).

$$
T=\left(t_{i j}\right)_{m \times n}=\left(w_{j} r_{i j}\right)_{m \times n^{\prime}} i=1,2, \ldots, m \quad w_{j}=\frac{W_{j}}{\sum_{j=1}^{n} W_{j}}, j=1,2, \ldots, n \quad \sum_{j=1}^{n} w_{j}=1
$$

and $W_{j}$ is the original weight given to the indicator $v_{j}, j=1,2, \ldots, n$.

Additionally, weighting can be considered without calculation by expert opinion. There are many methods to calculate the weighting matrix such as the entropy method [45]. In this paper, the same weighting for the amount of precipitation and frequency was assumed because two parameters are used as criteria $(n)$. The entropy method is usually used in the case of more than two parameters.

Step Four: Calculate the worst $A_{w}$ and best $A_{b}$ alternative.

$$
\begin{gathered}
A_{w}=\left\{\left\langle\max \left(t_{i j}|i=1,2, \ldots, m| j \in J_{-}\right\rangle,\left\langle\min \left(t_{i j}|i=1,2, \ldots, m| j \in J_{+}\right\rangle\right\} \equiv\left\{t_{w j} \mid i=1,2, \ldots, n\right\}\right.\right. \\
A_{b}=\left\{\left\langle\min \left(t_{i j}|i=1,2, \ldots, m| j \in J_{-}\right\rangle,\left\langle\max \left(t_{i j}|i=1,2, \ldots, m| j \in J_{+}\right\rangle\right\} \equiv\left\{t_{b j} \mid j=1,2, \ldots, n\right\}\right.\right.
\end{gathered}
$$

where $J_{+}=\{j=1,2, \ldots, n \mid j\}$ is associated with the criteria having a positive impact, and $J_{-}=$ $\{j=1,2, \ldots, n \mid j\}$ is associated with the criteria having a negative impact. In this article, precipitation has a negative impact and frequency has a positive impact. In other words, if the precipitation is more and frequency is less, the condition will be worse. If the precipitation is less and frequency is more, the condition will be better. $A_{w}$ is the worst alternative which has the highest precipitation and lowest frequency. $A_{b}$ is the best alternative which has the lowest precipitation and most frequency. The worst cases are considered because of alert levels determination.

Step Five: Determine each alternative distance to the best and the worst alternative. The distance between the target alternative $i$ and the worst condition $A_{w}$ is calculated by

$$
d_{i w}=\sqrt{\sum_{j=1}^{n}\left(t_{i j}-t_{w j}\right)^{2}}, i=1,2, \ldots, n
$$

and the distance between the alternative $i$ and the best condition $A_{b}$ is calculated by

$$
d_{i b}=\sqrt{\sum_{j=1}^{n}\left(t_{i j}-t_{b j}\right)^{2}}, i=1,2, \ldots, m
$$

Step Six: Similarity to the worst condition is calculated by

$$
s_{i w}=\frac{d_{i w}}{\left(d_{i w}+d_{i b}\right)}, 0 \leq s_{i w} \leq 1, i=1=1,2, \ldots, m
$$

$s_{i w}=1$, if and only if the alternative solution has the best condition

$s_{i w}=0$, if and only if the alternative solution has the worst condition

Step Seven: Alternatives are evaluated and ranked as $s_{i w}(i=1,2, \ldots, m)$ 
Therefore, each precipitation value has a unique rank. Precipitation is associated with $s_{i w}=0$ which has the highest rank and precipitation is associated with $s_{i w}=1$ which has the lowest rank.

All these steps were implemented in 87 stations for all months, seasons and years. At the end, each station and timeframe was ranked. The ranks were sorted in descending order. Precipitations corresponding with respective ranks were identified. The kriging method was used to interpolate the results. There are many spatial analyses to interpolate data. IDW (Inverse Distance Weighted), Spline and kriging were compared in the study area by Faraji and Azizi [46]. They found that the results of the kriging method were better than the other methods.

\section{Results and Discussion}

The model implemented in this article is based on the assumption that rare and unusual rainfall events in a certain geographic area occur infrequently and in high amounts.

The highest rank and $5 \%, 10 \%, 15 \%$, and $20 \%$ of the highest rank of results were selected. By doing this, five alert levels were determined. Rainfalls were identified with respect to these ranks for each station. The results varied for each station and in order to make a decision on the alert level at monthly and seasonal levels, interpolated maps using the kriging method were produced. In these maps, different cities and areas were shown with rainfalls corresponding to the alert levels at the given timeframe. According to the calculations, five alert levels were determined as follows:

\subsection{Level 1-Purple Status: The First Level of Warning}

This is the highest alert level. This condition means that the worst ideal alternative has happened. It means that the amount of precipitation is equal to or more than the highest value recorded in the climate period in each station. If the forecast is close to the zoning of this alert level in any month or time, then the region will experience dangerous conditions. It requires immediate action by the crisis management team and public services. Figure 2 shows the corresponding rainfall alert status by purple zoning for the seasons.

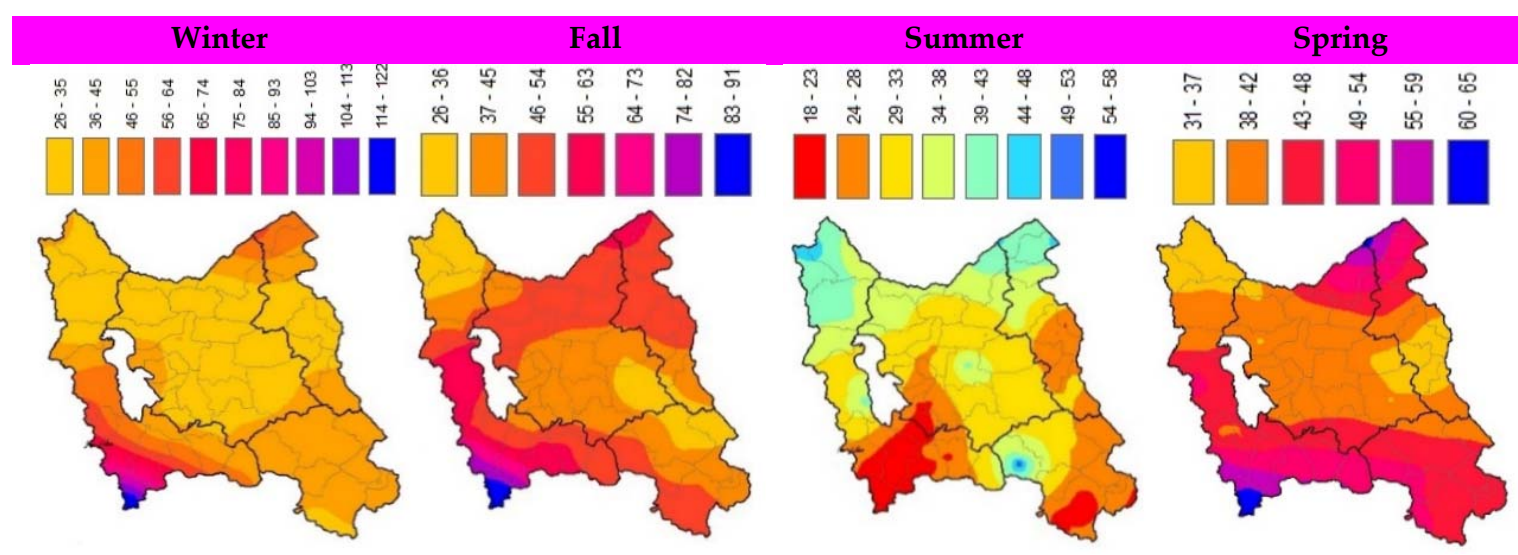

Figure 2. The first level of warning (purple status) in northwest Iran in different seasons.

Rainfall values vary in alert level 1 (purple) as shown in Figure 2. They depend on location and season. For example, if precipitation prediction indicates between 18 and 28 millimeters of rainfall, then alert level 1 (purple) should be issued in the summer of the southern part of the West Azarbayjan and Zanjan provinces. However, the same alert should only be issued when precipitation reaches more than 114 millimeters in the winter of the southern part of the West Azarbayjan province. The same applies to other regions and seasons. 


\subsection{Level 2-Red Status: The Second Level of Warning}

This is when rainfall corresponds to the top 5 percent of the TOPSIS ranking. Zoning for this alert level is done for all cities. If rainfall prediction is close to these zoning values, then alert level 2 (red) should be issued. Zoning corresponding to the precipitation of alert level 2 (red) is shown in Figure 3 . As an example, in the summer of north Azarbayjan and Ardebil provinces, rainfalls between 24 and $31 \mathrm{~mm}$ will result in the issuance of alert level 2 (red) while in the same season, in the south and east of the region, rainfall between 16 and $21 \mathrm{~mm}$ will raise the same alert level.

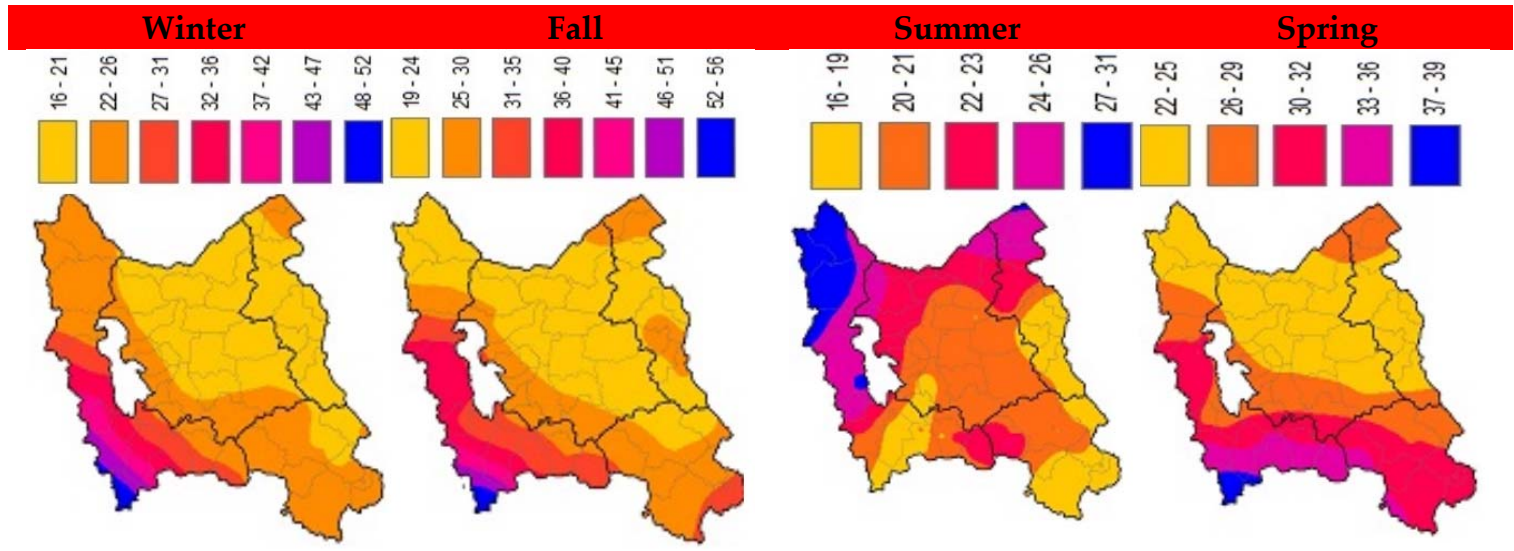

Figure 3. The second level of warning (red status) in northwest Iran in different seasons.

\subsection{Level 3-Orage Status: The Third Level of Warning}

This alert level is raised when rainfall corresponding to the top 10 percent of the TOPSIS ranking is observed. Precipitation values in this alert level are illustrated in Figure 4 below. Figure 4 shows that in the same region, different rainfalls will raise the alert in different seasons. For example, in the majority of Ardabil province, rainfall that will raise alert level 3 (orange) is between $16 \mathrm{~mm}$ and $20 \mathrm{~mm}$ in the spring, $11 \mathrm{~mm}$ and $20 \mathrm{~mm}$ in the summer, $13 \mathrm{~mm}$ and $24 \mathrm{~mm}$ in the autumn, and $13 \mathrm{~mm}$ and $18 \mathrm{~mm}$ in the winter.

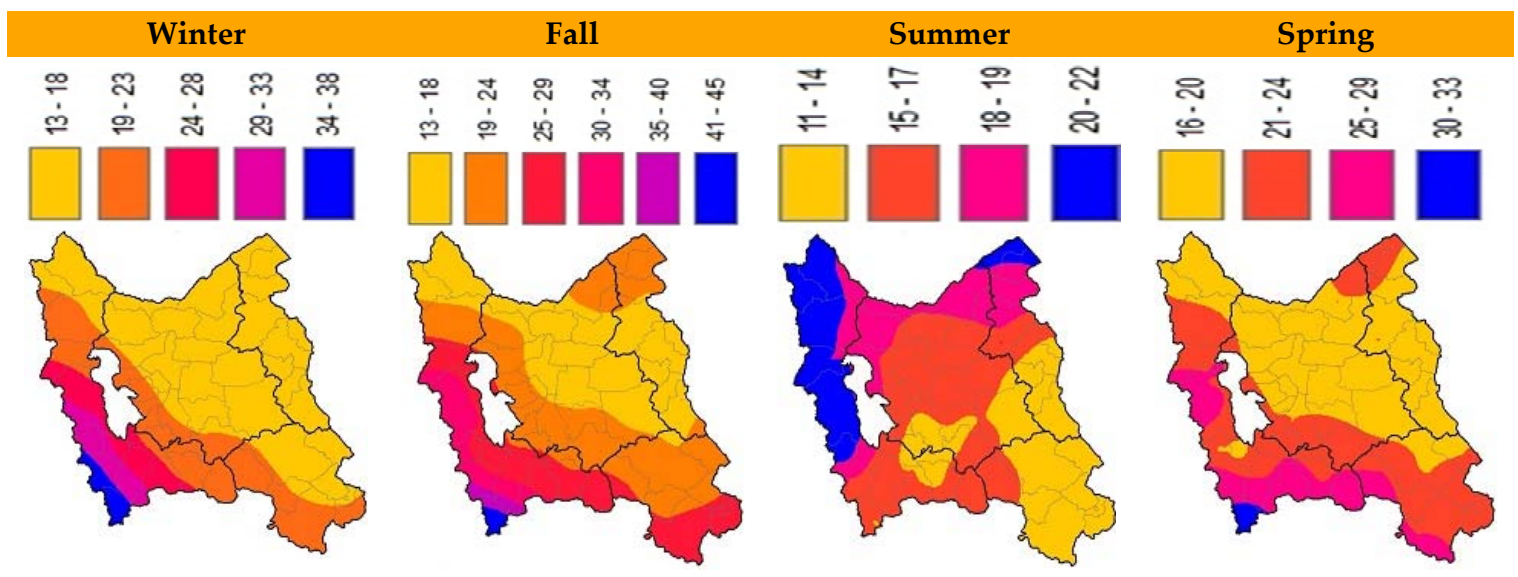

Figure 4. The third level of warning (orange status) in northwest Iran in different seasons.

\subsection{Level 4-Yellow Status and Level 5-Green Status: The Fourth and Fifth Level of Warning}

Rainfall corresponding to the top 15 percent of the TOPSIS ranking means that the fourth alert level (yellow) is raised and rainfall corresponding to the top 20 percent of the TOPSIS ranking raises the fifth alert level (green). The results are illustrated in Figures 5 and 6 below. Both alert levels 4 and 5 
can be considered part of the Group Announcements category, whereas alert levels 1 to 3 are placed in the category of warnings.

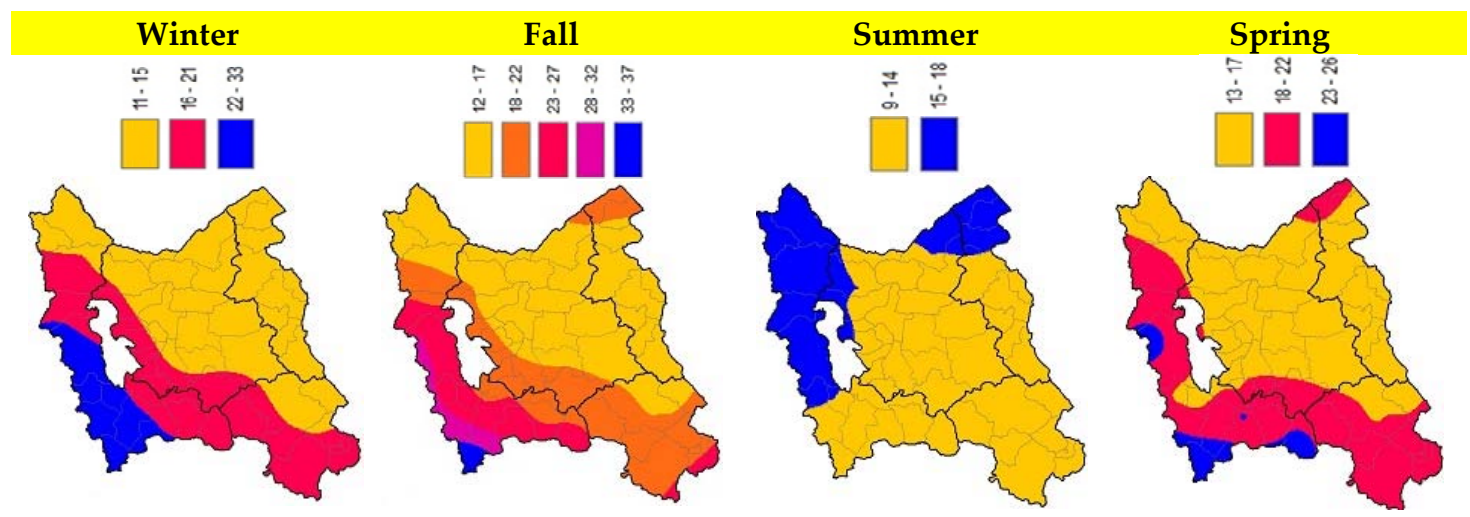

Figure 5. The fourth level of warning (yellow status) in northwest Iran in different seasons.
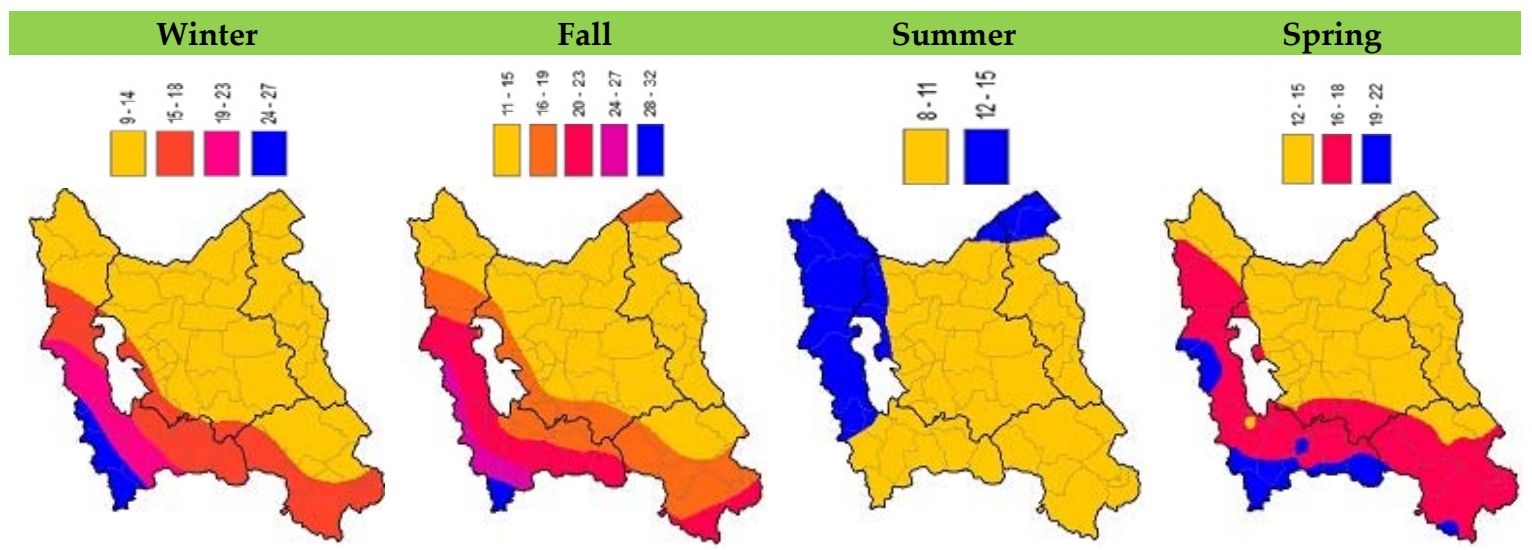

Figure 6. The fifth level of warning (Green status) in northwest Iran in different seasons.

\subsection{Compare Flood with the Alert Levels}

Floods were compared with these five alert levels in the last ten years. They had good conformity with the alert levels. For example, according to Figures 5 and 6, rainfalls between 8 and $18 \mathrm{~mm}$ can potentially cause flash flooding (yellow and green alert levels) in summer. In the last ten years, in the summer, $80 \%$ of floods have occurred at yellow and green alert levels while $20 \%$ of floods have occurred at red and purple alert levels.

As a practical example, flooding has been recorded in three regions (Shabstar, Tabriz and Bostanabad) on 24 June 2016. Precipitation was recorded at $10 \mathrm{~mm}$ in Shabstar, $4 \mathrm{~mm}$ in Bostanabad and $3 \mathrm{~mm}$ in Tabriz. Based on the fixed alert levels, rainfalls less than $10 \mathrm{~mm}$ do not need a weather warning. If TOPSIS alert levels had used, weather warnings would have been issued. Alert level maps produced for June and the location of floods, on 24 June 2016, are shown in Figure 7. Yellow warning for Bostanabad and Tabriz, and Orange warning for Shabstar can be issued according to the alert level maps in June. However, in the northwestern part of the area, rainfall less than $10 \mathrm{~mm}$ does not need a weather warning in June. 


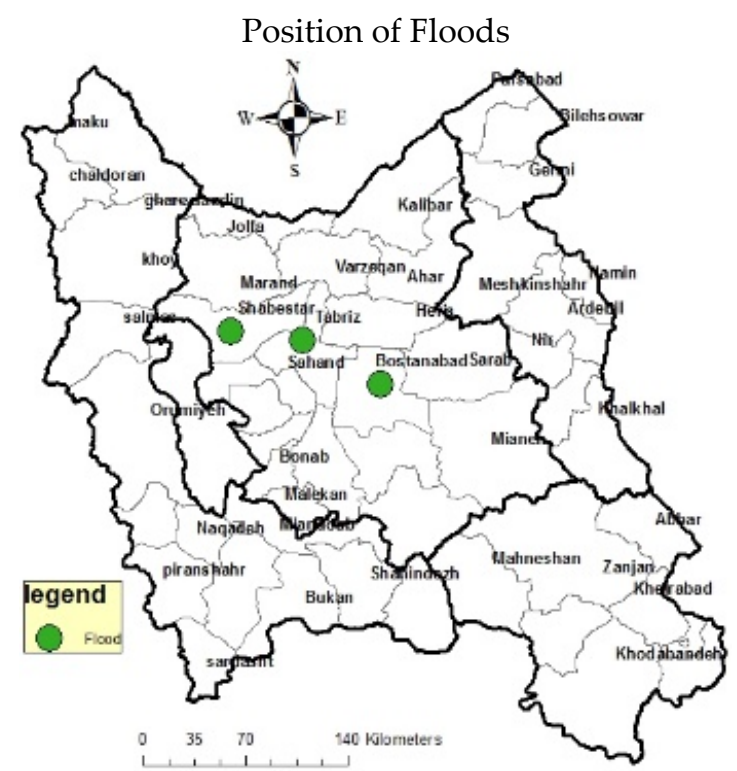

Orange warning

$=\stackrel{\circ}{\circ}$

¿̇ं

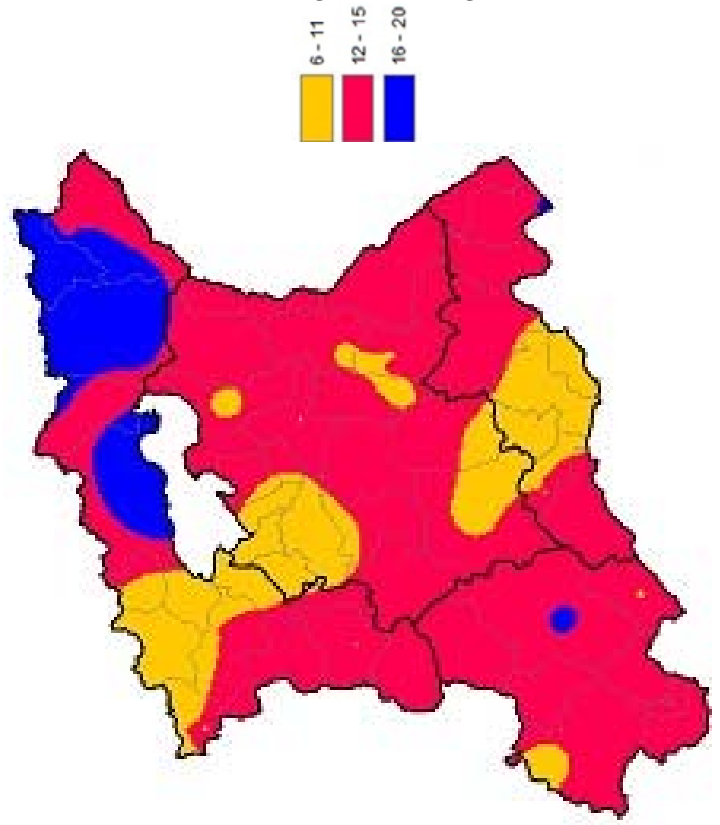

Green warning

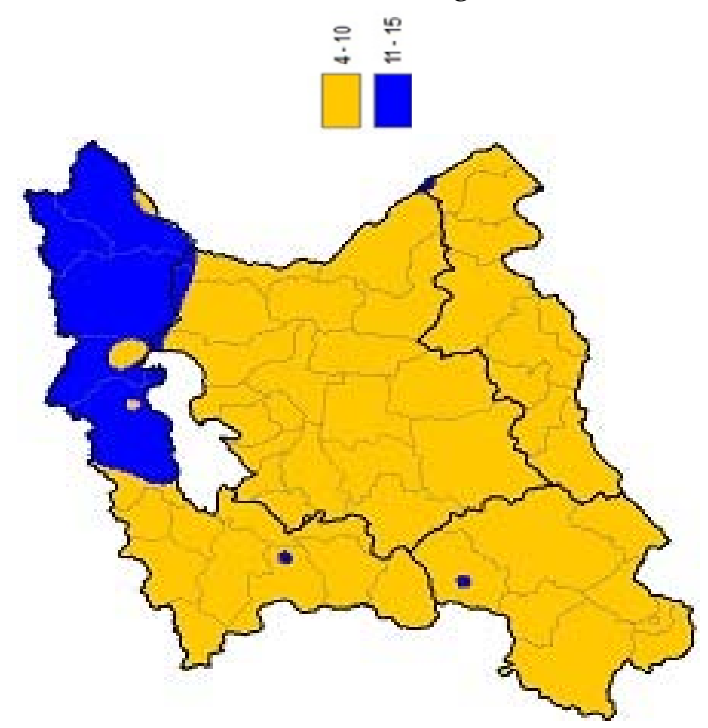

Yellow warning
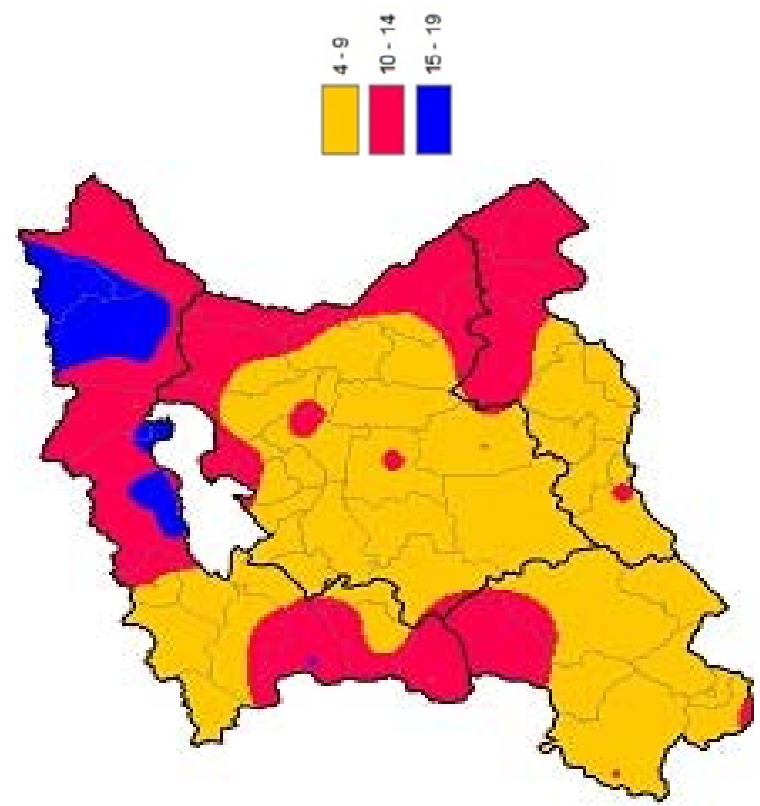

Figure 7. Location of floods on 24 June 2016 in northwest Iran and three alert levels based on the TOPSIS (The Order of Preference by Similarity to Ideal Solution) method.

\section{Conclusions}

Zoning of climate events in northwest Iran was carried out for five alert levels as detailed above. It has highlighted the importance of issuing warnings and announcements for weather conditions based on circumstances of location and season/time. It has been demonstrated that one location in different seasons will require different thresholds for raising an alert. As shown in Figure 3 to Figure 6, in a particular area, different rainfall amounts correspond to various alerts in different seasons. It was therefore also concluded that using annual fixed numbers as event thresholds and extending these fixed numbers to larger areas would disregard the seasonal conditions and could be grossly misleading.

In this study, the amount of rainfall and frequency were used to calculate the TOPSIS method. However, others parameters are involved in floods such as land cover, topography, soil penetration and so on. All of these parameters can be added to the TOPSIS method in order to complete this study. 
Acknowledgments: This study was funded by the corresponding author. Most of the data used in this research were collected from I.R. of Iran Meteorological Organization (IRIMO) and National Drought Warning and Monitoring Center (NDWMC) in Iran. We would like to thank all of those at these organizations, especially head of NDWMC Shahrokh Fateh

Author Contributions: This paper is the result of research conducted by Sadegh Zeyaeyan (SZ) as part of his PhD studies at the Atmospheric Science \& Meteorological Research Center. Ebrahim Fattahi (EF) and Abbas Ranjbar (AR) jointly supervised and Majid Vazifedoust (MV) jointly advisor this project. Model running was conducted by SZ with guidance from EF. AR. MV provided guidance on the analysis of the results. The manuscript was prepared by SZ with suggestions and corrections from EF and AR. All authors have seen and approved the final article.

Conflicts of Interest: The authors declare no conflict of interest.

\section{References}

1. Sura, P. Stochastic Models of Climate Extremes: Theory and Observations. Extremes in a Changing Climate-Detection, Analysis and Uncertainty; Springer: Berlin/Heidelberg, Germany, 2012; pp. 1-75.

2. Taghavi, F.; Naseri, M.; Bayat, B.; Motavaliyan, S.S.; Azadifard, D. The Determination of Climate Behavior Patterns in Different Parts of Iran on the Basis of Spectral Analysis and Clustering of Extreme Temperature and Precipitation Values; Physical Geography Researches Tehran University: Tehran, Iran, 2011; pp. 109-124.

3. Sheikh, M.M.; Ahmed, A.U.; Revadekar, J.V.; Shrestha, M.L.; Premlal, K.H.M.S. Development and Application Of Climate Extreme Indices and Indicators for Monitoring Trends in Climate Extremes and Their Socio-Economic Impacts in South Asian Countries; Final Report for APN Project: ARCP2008-10CMY-Sheikh; APN: Kobe, Japan, 2009; pp. 1-25.

4. Rahimzadeh, F.; Hedayat Dezfouli, M.; PourAsghariyan, A.; Asgari, V. Assess the extent and mutation profiles of temperature and precipitation in the Hormozgan Province. Geogr. Dev. 2007, 21, 97-116.

5. Easterling, D.R.; Meehl, G.A.; Parmesan, C.; Changnon, S.A.; Karl, T.R.; Mearns, L.O. Climate extremes: Observations, modeling, and impacts. Science 2000, 289, 2068-2074. [CrossRef] [PubMed]

6. Manton, M.J.; Della-Marta, P.M.; Haylock, M.R.; Hennessy, K.J.; Nicholls, N.; Chambers, L.E.; Collins, D.A.; Daw, G.; Finet, A.; Gunawan, D.; et al. Trend in extreme daily rainfall and temperature in Southeast Asia and South Pacific. Int. J. Clim. 2001, 21, 269-284. [CrossRef]

7. Klein Tank, A.M.G.K.; Können, G.P. Trends in indics of daily temperature and precipitation extremes in Europe. J. Clim. 2003, 16, 3665-3680. [CrossRef]

8. Hansen, J.; Sato, M.; Ruedy, R.; Lacis, A.; Oinas, V. Global warming in the twenty-first century: An alternative scenari. Proc. Natl. Acad. Sci. USA 2000. [CrossRef] [PubMed]

9. Hansen, J.; Sato, M.; Ruedy, R. Perception of climate change. Proc. Natl. Acad. Sci. USA 2012, 109, E2415-E2423. [CrossRef] [PubMed]

10. Gholami, V.; Chau, K.W.; Fadaee, F.; Torkaman, J.; Ghaffari, A. Modeling of groundwater level fluctuations using dendrochronology in alluvial aquifers. J. Hydrol. 2015, 529, 1060-1069. [CrossRef]

11. Taormina, R.; Chau, K.W. Data-driven input variable selection for rainfall-runoff modeling using binary-coded particle swarm optimization and Extreme Learning Machines. J. Hydrol. 1987, 529, 1617-1632. [CrossRef]

12. Wu, C.L.; Chau, K.W.; Li, Y.S. Methods to improve neural network performance in daily flows prediction. J. Hydrol. 2009, 372, 80-93. [CrossRef]

13. Wang, W.C.; Chau, K.W.; Xu, D.; Chen, X.Y. Improving forecasting accuracy of annual runoff time series using ARIMA based on EEMD decomposition. Water Resour. Manag. 2015, 29, 2655-2675. [CrossRef]

14. Chen, X.Y.; Chau, K.W.; Busari, A.O. A comparative study of population-based optimization algorithmsfor downstream river flow forecasting by a hybrid neural network model. Eng. Appl. Artif. Intell. 2015, 46, 258-268. [CrossRef]

15. Chau, K.W.; Wu, C.L. A hybrid model coupled with singular spectrum analysis for daily rainfallprediction. J. Hydroinf. 2010, 12, 458-473. [CrossRef]

16. UK. METoffice. Available online: http://www.metoffice.gov.uk/guide/weather/warnings (accessed on 11 December 2015).

17. MET ÉIREANN. 2016. Available online: http://www.met.ie/nationalwarnings/warnings-explained.asp (accessed on 13 July 2016). 
18. Folland, C.K.; Karl, T.R.; Christy, J.R.; Clarke, G.V.; Gruza, G.V.; Jouzel, J.; Mann, M.E.; Oerlemans, J.; Salinger, M.J.; Wang, S.W. Climate Change 2001: The Scientific Basis; IPCC: Geneva, Switzerland, 2007; pp. 155-163.

19. Houghton, J.T.; Ding, Y.; Griggs, D.J.; Noguer, M.; van der Linden, P.J.; Dai, X.; Maskell, K.; Johnson, C.A. IPCC, 2001: Climate Change 2001: The Scientific Basis. Contribution of Working Group I to the Third Assessment Report of the Intergovermental Panel on Climate Change; World Meteorological Organization/United Nations Environment Programme, Cambridge University Press: Cambridge, UK; New York, NY, USA, 2001; p. 881.

20. Gleason, K.L.; Lawrimore, J.H.; Levinson, D.H.; Karl, T.R.; Karoly, D.J. A Revised U.S. Climate extremes index. J. Clim. 2007, 21. [CrossRef]

21. National Oceanic and Atmospheric Administration (NOAA). Available online: http:/ /www.srh.noaa.gov/ bro/?n=mapcolors (accessed on 24 April 2015).

22. Saaty, T.L. Analytic Hierarchy Process: Planning, Priority Setting, Resource Allocation; McGraw-Hill: New York, NY, USA, 1980.

23. Zavadskas, E.K.; Zakarevicius, A.; Antucheviciene, J. Evaluation of ranking accuracy in multi-criteria decisions. Informatica 2006, 17, 601-618.

24. Asakereh, H.; Ramzi, R. Climatology of precipitation in North West of Iran. Geogr. Dev. 2012, 9, 137-158.

25. Karl, T.R.; Williams, C.N. An approach to adjusting climatological time series for discontinuous inhomogeneities. J. Clim. Appl. Meteorol. 1987, 26, 1744-1763. [CrossRef]

26. Rhoades, D.A.; Salinger, M.J. Adjustment of temperature and rainfall records for site changes. Int. J. Climatol. 1993, 13, 899-913. [CrossRef]

27. Buishand, T.A. Some methods for testing the homogeneity of rainfall records. J. Hydrol. 1982. [CrossRef]

28. Alexanderson, H.A. A homogeneity test applied to precipitation data. J. Climatol. 1986, 6, 661-675. [CrossRef]

29. Chakravarti, I.M.; Laha, R.G.; Roy, J. Handbook of Methods of Applied Statistics; John Wiley and Sons: Hoboken, NJ, USA, 1967; Volume 1, pp. 392-394.

30. Javari, M. Trend and homogeneity analysis of precipitation. Climate 2016, 4, 44. [CrossRef]

31. González-Rouco, J.F.; Jiménez, J.L.; Quesada, V.; Valero, F. Quality control and homogeneity of precipitation data in the Southwest of Europe. J. Clim. 2000, 14, 964-978. [CrossRef]

32. Machiwal, D.; Madan, K.J.H.A. Comparative evaluation of statistical tests for time series analysis: Application to hydrological time series/Evaluation comparative de tests statistiques pour l'analyse de séries temporelles: Application à des series temporelles hydrologiques. Hydrol. Sci. J. 2008, 53, 353-366. [CrossRef]

33. Hwang, C.L.; Yoon, K. Multiple Attribute Decision Making: Methods and Applications; Springer: New York, NY, USA, 1981.

34. Yoon, K. A reconciliation among discrete compromise situations. J. Oper. Res. Soc. 1987, 38, 277-286. [CrossRef]

35. Hwang, C.L.; Lai, Y.J.; Liu, T.Y. A new approach for multiple objective decision making. Comput. Oper. Res. 1993, 20, 889-899. [CrossRef]

36. Qangormeh, A.; Roshan, G. Application of TOPSIS index in monitoring of drought and wet in Golestan Province. J. Earth Space Phys. 2015, 41, 536-547.

37. Azmi, M.; Araghinejad, S.; Sarmadi, F. A national-scale assessment of agricultural development feasibility using Multi-Criteria Decision Making (MCDM) approaches. Adv. Nat. Appl. Sci. 2011, 5, 379.

38. Assari, A.; Mahesh, T.; Assari, E. Role of public participation in sustainability of historical city: Usage of TOPSIS method. Indian J. Sci. Technol. 2012, 5, 2289-2294.

39. Wang, Y.M.; Elhag, T.M. Fuzzy TOPSIS method based on alpha level sets with an application to bridge risk assessment. Expert Syst. Appl. 2006, 31, 309-319. [CrossRef]

40. Wang, T.C.; Chang, T.H. Application of TOPSIS in evaluating initial training aircraft under fuzzy environment. Expert Syst. Appl. 2007, 33, 870-880. [CrossRef]

41. Chen, Y.; Li, K.W.; Liu, S. An OWA-TOPSIS method for multiple criteria decision analysis. Expert Syst. Appl. 2011, 38, 5205-5211. [CrossRef]

42. Greene, R.; Devillers, R.; Luther, J.E.; Eddy, B.G. GIS-based multi-criteria analysis. Geogr. Compass 2011, 412-432. [CrossRef]

43. Yoon, K.P.; Hwang, C. Multiple Attribute Decision Making: An Introduction; SAGE Publications: Thousand Oaks, CA, USA, 1995. 
44. Huang, I.B.; Keisler, J.; Linkov, I. Multi-criteria decision analysis in environmental science: Ten years of applications and trends. Sci. Total Environ. 2011, 409, 3578-3594. [CrossRef] [PubMed]

45. KhoshAkhlagh, F.; Hejazizadeh, Z.; Mohammadi, H.; Roshan, G. The approach of TOPSIS method for determining and ranking drought: Drought case study zoning few stations in Khuzestan Province. J. Appl. Res. Geogr. Sci. 2006, 5, 105-127.

46. Faraji, H.; Azizi, G. Evaluation of spatial interpolation methods. Phys. Geogr. Res. Q. 2006, 58, 1-15.

(C) 2017 by the authors. Licensee MDPI, Basel, Switzerland. This article is an open access article distributed under the terms and conditions of the Creative Commons Attribution (CC BY) license (http:/ / creativecommons.org/licenses/by/4.0/). 